\title{
Syphilis notifications among pregnant women in Campo Grande, state of Mato Grosso do Sul, Brazil, 2011 to 2017
}

\section{Cássia de Paula Pires ${ }^{[1]}$, Caroliny Oviedo Fernandes ${ }^{[2]}$, Everton Falcão de Oliveira ${ }^{[1],[3]}$, Sandra Luzinete Felix de Freitas ${ }^{[3]}$ and Rodrigo Guimarães dos Santos Almeida ${ }^{[3]}$}

\begin{abstract}
[1]. Universidade Federal de Mato Grosso do Sul, Programa de Pós-Graduação em Doenças Infecciosas e Parasitárias, Campo Grande, MS, Brasil. [2]. Universidade Federal de Mato Grosso do Sul, Programa de Residência em Enfermagem Obstétrica, Campo Grande, MS, Brasil.
\end{abstract}

[3]. Universidade Federal de Mato Grosso do Sul, Instituto Integrado de Saúde, Campo Grande, MS, Brasil.

\begin{abstract}
Introduction: Syphilis is a sexually transmitted infection caused by Treponema pallidum. Considering the high rates of syphilis in pregnancy and congenital syphilis reported in Brazil in the past, and their serious consequences, this study described the epidemiological and clinical profile of pregnant women with a confirmed diagnosis of syphilis in Campo Grande, in the state of Mato Grosso do Sul, Brazil, from 2011 to 2017. Methods: This is a descriptive study, based on syphilis notifications among pregnant women reported to the Sistema de Informação de Agravos de Notificação (National System of Disease Notification of Brazil). Results: Over the study period, 2,056 confirmed cases of syphilis in pregnancy were reported, resulting in a crude cumulative incidence of 144.76 cases per 1,000 liveborn babies. The incidence increased from 9.97 cases per 1,000 live-born babies in 2011 to 36.10 cases per 1,000 live-born babies in 2017. It was more prevalent in women who were young, of mixed race, with low educational attainment. Over one third of women were diagnosed in the first trimester of pregnancy; therefore, they were at risk of reinfection if they or their sexual partners were inadequately treated. Furthermore, syphilis was not well classified according to its clinical stage, which led to inappropriate treatments. Conclusions: Despite efforts to reduce the incidence of syphilis, syphilis during pregnancy remains a public health problem, reflecting possible inadequacies in antenatal care, especially in vulnerable populations. It is important to include sexual partners in syphilis treatment during pregnancy to prevent reinfection.
\end{abstract}

Keywords: Treponemal infections. Antenatal care. Treponema pallidum. Syphilis. Congenital syphilis.

\section{INTRODUCTION}

Syphilis is an infectious disease caused by Treponema pallidum, which has cutaneous and systemic manifestations. Treponemal and non-treponemal tests are used in diagnosis, and benzathine penicillin is the standard treatment. There are four stages of infection: primary, secondary, tertiary, and latent. The required dose and duration of antibiotic treatment depends on the stage: the more advanced the stage, the greater the required dose $\mathrm{e}^{1,2}$.

According to the World Health Organization, syphilis affects more than 12 million people worldwide, with 2 million pregnant

\footnotetext{
Corresponding author: Cássia de Paula Pires.

e-mail: cassia_ppires@hotmail.com

(D) https://orcid.org/0000-0003-0487-068X

Received 28 January 2020

Accepted 28 May 2020
}

women infected annually ${ }^{3}$. Syphilis in pregnancy can cause congenital syphilis, which may have serious health consequences.

Congenital syphilis is a disease of public health importance because it can cause early and late complications in infants, including premature birth, low birth weights, skin lesions, periostitis or osteitis, anemia, and seizures ${ }^{4}$. In 2013, congenital syphilis caused more than 300,000 fetal and neonatal deaths, and more than 215,000 childhood deaths worldwide ${ }^{2}$. The incidence rate of congenital syphilis in Brazil was 9.0 cases per 1,000 live births in $2018^{3}$. In 2016, the Plan of Action for the Prevention and Control of HIV and Sexually Transmitted Infections (2016-2021) was released, and prevention measures, including increased access to diagnosis and early treatment of HIV infection and other sexually transmitted infections (STIs), were expanded to reduce their incidence by $2021^{5}$.

The persistently high incidence of syphilis is a major public health problem in Brazil, with serious consequences ${ }^{2}$. Management 
of the consequences of this disease, especially the tertiary form in adults and congenital syphilis, is costly in terms of healthcare resources.

This study aimed to estimate the incidence of syphilis in pregnancy as well as congenital syphilis, and to describe the epidemiological and clinical-obstetric features of the reported and confirmed cases of syphilis in pregnant women in Campo Grande, Mato Grosso do Sul State, Brazil.

\section{METHODS}

We conducted a descriptive and retrospective study based on syphilis cases in pregnant women and congenital syphilis reports from the Sistema de Informação de Agravos de Notificação (National System of Disease Notification of Brazil - Brazilian abbreviation: SINAN) in Campo Grande, from 2011 to 2017. All data were provided by the Municipal Secretary of Public Health of Campo Grande.

All cases of syphilis in pregnant women in Campo Grande that were confirmed using treponemal and/or non-treponemal tests, who also did not have a previous treatment record, were included. Cases reported outside the study period, cases of syphilis in pregnant women living in other municipalities or in rural and peri-urban areas, and women who were seropositive from a previous infection were excluded.

The data included age, racial origin, marital status, level of education, the trimester of diagnosis, clinical data on diagnosis and treatment of the pregnant women (including clinical classification, treponemal and non-treponemal test results, and the treatment provided); it also included data on treatments received by sexual partners (treatment completion, therapy used, and reason for nontreatment), and infants born to women with syphilis during pregnancy.

Analyses were performed using Statistical Package for Social Sciences version 22 (IBM Corp., Armonk, NY, USA).

The study protocol was approved by the Universidade Federal de Mato Grosso do Sul Research Ethics Committee (CAAE: 69740517.8.0000.0021; protocol: 2.166.457), which granted a waiver of the requirement for consent, and the study was conducted in accordance with the principals of the Declaration of Helsinki.

\section{RESULTS}

During the study period, 2,255 cases of syphilis in pregnant women were notified and recorded in SINAN. After applying the exclusion criteria, 2,056 cases were included in the analysis. The highest syphilis frequency in 2017 was almost 4 times higher than that in 2011, and the crude incidence cumulative per year continuously increased (Table 1).

The incidence was highest in women in the 20-29 years age group, followed by those in the 10-19 years age group (Table 2). More than half of the cases occurred among women of mixed race, and the incidence was higher among women with less than 10 years of schooling than among women with a higher level of education. Over one third of the women were in the first trimester of pregnancy at the time of diagnosis (Table 2).

Of the women with information on the clinical stage at the time of diagnosis, the majority were in the tertiary or latent phase, and the majority of infections were confirmed by treponemal tests (Table 3 ).

In order to consider a pregnant woman as having been adequately treated in this study, treatment should be terminated within 30 days before delivery, should occur concurrently with the sexual partner's treatment, and the dose of benzathine penicillin should be appropriate for the clinical phase ${ }^{2}$. Based on these criteria, treatment was considered adequate in less than half of pregnant women (Table 3).

The largest shortcoming in the management of syphilis among women in the study was the diagnosis and treatment of the sexual partners of women reported with syphilis during pregnancy. Diagnostic tests and treatment were not performed in almost half of the partners. Therefore, their treatment could be considered inadequate as well as the lack of contact with the pregnant woman and partners who did not attend the health unit when requested (Table 4).

A total of 907 cases of congenital syphilis were reported among the 2,056 women reported with syphilis during pregnancy in Campo Grande from 2011 to 2017. Thus, 44.1\% of women with syphilis diagnosed during pregnancy had an unfavorable outcome with serious consequences for their babies, such as miscarriages, stillbirths, prematurity, and other clinical manifestations ${ }^{2}$.

TABLE 1: Frequencies of live-born, reported cases of syphilis diagnosed in pregnant women, and the crude incidence per 1,000 live-born babies, according to the year $(\mathrm{N}=2,056)$.

\begin{tabular}{lccr}
\hline Year & Population (live births) & Reported cases & Incidence (1000 inhabitants) \\
\hline 2011 & 13,045 & 130 & 9.97 \\
2012 & 13,539 & 193 & 14.26 \\
2013 & 13,693 & 249 & 18.18 \\
2014 & 14,203 & 243 & 328.11 \\
2015 & 14,470 & 398 & 22.67 \\
2016 & 13,728 & 515 & 28.99 \\
2017 & 14,264 & 36.10 &
\end{tabular}


TABLE 2: Sociodemographic characteristics of women reported with syphilis during pregnancy $(N=2,056)$.

\begin{tabular}{|c|c|c|}
\hline Variables & $\mathbf{N}$ & $\%$ \\
\hline \multicolumn{3}{|l|}{ Age (years) } \\
\hline 10 to 19 & 533 & 25.9 \\
\hline 20 to 29 & 1034 & 50.3 \\
\hline 30 to 39 & 435 & 21.2 \\
\hline$\geq 40$ years & 54 & 2.6 \\
\hline \multicolumn{3}{|l|}{ Race } \\
\hline Asian & 16 & 0.8 \\
\hline Indigenous & 23 & 1.1 \\
\hline Black & 129 & 6.3 \\
\hline White & 605 & 29.4 \\
\hline Mixed & 1160 & 56.4 \\
\hline Missing/unreported & 123 & 6.0 \\
\hline \multicolumn{3}{|c|}{ Age at completing schooling } \\
\hline$<10$ years old & 843 & 41.0 \\
\hline From 10 to 12 years old & 700 & 34.0 \\
\hline$>12$ years old & 57 & 2.8 \\
\hline Missing/unreported & 456 & 22.2 \\
\hline \multicolumn{3}{|l|}{ Trimester of infection } \\
\hline First & 714 & 34.7 \\
\hline Second & 617 & 30.0 \\
\hline Third & 556 & 27.0 \\
\hline Missing/unreported & 169 & 8.3 \\
\hline \multicolumn{3}{|l|}{ Region of residence } \\
\hline Anhanduizinho & 699 & 34.0 \\
\hline Bandeira & 286 & 13.9 \\
\hline Centro & 49 & 2.4 \\
\hline Imbirussu & 218 & 10.6 \\
\hline Lagoa & 344 & 16.7 \\
\hline Prosa & 167 & 8.1 \\
\hline Segredo & 282 & 13.7 \\
\hline Missing/unreported & 11 & 0.6 \\
\hline
\end{tabular}

TABLE 3: Clinical characteristics and treatment of women reported with syphilis during pregnancy $(N=2,056)$.

\begin{tabular}{|c|c|c|}
\hline Variants & $\mathbf{N}$ & $\%$ \\
\hline \multicolumn{3}{|l|}{ Clinical stage } \\
\hline Primary & 354 & 17.2 \\
\hline Secondary & 40 & 1.9 \\
\hline Tertiary & 590 & 28.7 \\
\hline Latent & 510 & 24.8 \\
\hline Missing/unreported & 562 & 27.3 \\
\hline \multicolumn{3}{|l|}{ Treponemal test } \\
\hline Reactive & 1872 & 91.1 \\
\hline Non-reactive & 29 & 1.4 \\
\hline Missing/invalid & 155 & 7.5 \\
\hline \multicolumn{3}{|l|}{ Non-treponemal test } \\
\hline Reactive & 1254 & 61.0 \\
\hline Non-reactive & 260 & 12.6 \\
\hline Missing/invalid & 542 & 26.4 \\
\hline \multicolumn{3}{|c|}{ Treatment of pregnant woman } \\
\hline Appropriate & 1006 & 48.9 \\
\hline Inappropriate & 1050 & 51.1 \\
\hline
\end{tabular}


TABLE 4: Clinical characteristics and treatment of sexual partners of women reported with syphilis during pregnancy $(\mathrm{N}=2,056)$.

\begin{tabular}{|c|c|c|}
\hline Variants & $\mathbf{N}$ & $\%$ \\
\hline \multicolumn{3}{|l|}{ Test performed } \\
\hline Yes & 1056 & 51.4 \\
\hline No & 873 & 42.5 \\
\hline Missing/ unreported & 127 & 6.2 \\
\hline \multicolumn{3}{|l|}{ Therapeutic scheme } \\
\hline Appropriate & 569 & 27.5 \\
\hline Inappropriate & 803 & 38.9 \\
\hline Unperformed & 684 & 33.1 \\
\hline \multicolumn{3}{|l|}{ Reasons for non-treatment of the partner } \\
\hline Lack of contact with the pregnant woman & 365 & 17.8 \\
\hline Partner did not attend & 135 & 6.6 \\
\hline Partner's identity was not reported & 16 & 0.8 \\
\hline Partner had a non-reactive test result & 66 & 3.2 \\
\hline Partner refused & 50 & 2.4 \\
\hline Other & 264 & 12.8 \\
\hline Missing & 1160 & 56.4 \\
\hline
\end{tabular}

\section{DISCUSSION}

During the study period, there was a continuous and marked increase in the incidence of syphilis diagnosed during pregnancy. Considering the introduction of mandatory notifications of gestational syphilis in Brazil in 2005, this continuous increase may result in improvements in the reporting system due to better human resource capacities, a pregnant women's increased access to prenatal consultations as a result of the implementation of Family Health Strategy teams, and increased epidemiological surveillance. Such actions are aimed at improving women's health during antenatal care in order to achieve a reduction in gestational and congenital syphilis ${ }^{6,7}$. However, other possible causes must be considered, such as those related to behavioral issues ${ }^{8}$.

Furthermore, there was a relatively high number of cases of syphilis diagnosed in pregnant adolescents. This is a cause of concern for health services because women reach reproductive age during adolescence. In addition, the number of cases of syphilis diagnosed in pregnant adolescents increased over the study period. In this study, adolescents accounted for $25.9 \%$ of the total number of cases of syphilis diagnosed during pregnancy. In other studies of syphilis among pregnant women conducted in Brazil between 2010 and 2014, adolescents accounted for less than $20 \%$ of cases of syphilis diagnosed during pregnancy $y^{9,10,11}$.

Studies have shown that people of mixed race and a lower level of education have a higher incidence of STIs. This has been attributed to a lack of information about prevention and treatment, and a high incidence of unprotected sex among women in these demographic groups ${ }^{12,13}$. Macêdo et al. showed that the incidence of syphilis during pregnancy was higher among women of low socioeconomic status and among those who received inadequate antenatal care $^{14}$. In addition, unsafe sexual practices and lack of social support have been shown to increase the risk of recurrent infections and reinfection ${ }^{14}$.

The determinants of syphilis and congenital syphilis are not only related to the quality of antenatal care offered to women, but are rooted in the social, economic, cultural, and behavioral factors that women experience. During pregnancy, early diagnosis is critical in order to reduce the risk of vertical transmission. This is because in the early stages of infection there is a higher number of circulating spirochetes and a higher risk of transmission to the fetus ${ }^{1}$.

In terms of the clinical stages seen in this study, the majority of the women were in the tertiary or latent phase. This differs from the frequencies reported in other studies, where most cases were in the primary phas $\mathrm{e}^{15,16}$. In these other studies, the pregnant women might have been classified incorrectly, because if screening were conducted, a higher proportion of women would be expected to be in the latent phase ${ }^{17}$. In addition, the more advanced the clinical stage, the greater the dose and duration of treatment that is required. Therefore, it is important that healthcare providers establish a good relationship with primary care users in order to minimize loss to follow-up, ${ }^{18}$ and to ensure that those who require prolonged treatment, particularly those with tertiary or latent syphilis, complete their full course of treatment. However, there were many women with missing data due to a failure on the part of the healthcare providers to complete all items on the notification form. This may have compromised the quality of the data.

Treponemal tests were used increasingly. Although confirmation of the diagnosis using treponemal tests is important, ideally treponemal tests should be performed together with a nontreponemal test. This makes it possible to correctly classify the clinical phase of the disease so that the appropriate dose and duration of treatment can be administered ${ }^{1}$.

Most of the women in this study received inadequate treatment. This is a concern because a lack of adequate treatment increases the risk of vertical transmission. Although the proportion of women who received adequate treatment was low $(48.9 \%)$, it was higher than the proportion reported in other municipalities, as evidenced by Teixeira et al. ${ }^{19}$, in which only $20 \%$ of the women received adequate treatment. In order to ensure adequate and appropriate treatment, it is essential to form a bond between the health professional, the 
pregnant woman, and her partner, highlighting the importance of the primary care network and committed health teams. The low rates of treatment of women's sexual partners could reflect problems with healthcare access among men; thus, the inclusion of men in antenatal care programs, in order to reduce the numbers of those who abandon treatment or receive inadequate treatment, is crucial.

Given that some pregnant women may not adhere to treatment, there is a need to improve the quality of care through tools such as the continuing education of professionals. This could be achieved by promoting programs such as the Permanent Education in Health, a program designed by the Ministry of Health that provides education to health professionals in their workplace, and aims to provide meaningful learning in order to transform professional practices in daily work ${ }^{20}$. In primary health care, active screening of pregnant women is essential to ensure that no cases are undiagnosed, and when syphilis is diagnosed, it is essential that all the items on the notification forms are filled-out accurately. This enables the profiles of the pregnant women with syphilis to be determined, thus making it possible to invest in appropriate methods of prevention. Continuing education should be provided to health professionals and the community, as knowledge regarding syphilis is fundamental for its prevention and control.

The low proportion of pregnant women in this study whose sexual partners were tested and treated for syphilis should not be attributed to the pregnant women alone, as men's health-seeking behavior may have led them to resist treatment. Many men report feelings of fear, shame, carelessness, lack of time to seek care, and a lack of support by the health service system ${ }^{21,22}$. In addition, one study found that women were afraid of experiencing violence or being labeled as unfaithful if they disclosed their diagnosis of syphilis to their partners ${ }^{23}$. Thus, even if women are adequately treated, they may be re-infected by their sexual partners. This highlights the need to make treatment more accessible and welcoming among this population ${ }^{6-15-21}$.

We found a high incidence of congenital syphilis among the infants of women diagnosed with syphilis during pregnancy. Congenital syphilis is the leading cause of neonatal death and congenital malformation. The high incidence rate of congenital syphilis indicates a failure of the healthcare system, especially in primary care where there is the possibility of intervention ${ }^{2-24}$.

The recent increase in the syphilis diagnosed during pregnancy indicates that despite the high coverage, antenatal care is insufficient to prevent, diagnose, and treat this infection adequately. The inadequate treatment of pregnant women and their partners highlights the vulnerability of these women, mainly because syphilis is an STI. The majority of these women were in the first and second trimesters of pregnancy at the time of diagnosis, and thus had a high risk of reinfection due to inappropriate treatment, for themselves or their sexual partners.

A limitation of this study is the amount of missing data in the disease notification forms. This highlights the need to improve the quality of reporting and case investigation. It also should be pointed out that it is possible that more male partners were treated than the number reflected in our data, but the deficiencies in the reporting methods could have led to them not being linked to their pregnant women partners. This study is likely to inspire research on syphilis during pregnancy, especially with respect to strategies to strengthen primary care. This will make it possible to achieve the goals related to the prevention of syphilis and a creating a better quality of life for pregnant women who are affected, as well as for their children.

There is need for continual improvement of the reporting system; and staff training should be carried out consistently in primary care. In addition, receptivity toward care and the formation of bonds between health professionals and primary care users is essential for successful care provision.

Finally, our results showed that social, economic, and cultural vulnerability influenced the occurrence of syphilis in different demographic groups of pregnant women, despite risk-reduction strategies on the part of the health services. The groups most affected by syphilis were the groups neglected based on their economic and social situations.

\section{ACKNOWLEDGMENTS}

We thank the Municipal Secretary of Public Health of Campo Grande for providing the data.

\section{FINANCIAL SUPPORT}

This study was financed in part by the Coordenação de Aperfeiçoamento de Pessoal de Nível Superior, Brasil (CAPES) (https://www.capes.gov.br/) - Financial Code 001, and by Universidade Federal de Mato Grosso do Sul (UFMS) (https://www.ufms.br/).

\section{AUTHORS' CONTRIBUTION}

CPP: involved in the planning, execution, analysis, interpretation, and writing of the research, together with the advisors and collaborators. Provided final approval of the version to be submitted. Involved in the conception and design of the study, and in the acquisition of the data; COF: involved in the planning, selection of the research area, and guidance in the execution and elaboration of the work. EFO: involved in the analysis and interpretation of data, drafting of the article, and provided final approval of the version to be submitted. SLFF: involved in the acquisition of data. Collaborated in the elaboration of spreadsheets for statistical analysis of the research. RGSA: involved in the conception and design of the study; involved in the planning, collaboration, correction, and contributions, in order to enrich the research and article for publication.

\section{CONFLICT OF INTEREST}

The authors declare that there is no conflict of interest.

\section{REFERENCES}

1. Avelleira JCR, Bottino G. Syphilis: diagnosis, treatment and control. An Bras Dermatol. 2006;81(2):111-26.

2. Ministério da Saúde (MS), Secretaria de Vigilância em Saúde. Protocolo Clínico e Diretrizes Terapêuticas para Prevenção da Transmissão Vertical de HIV, Sífilis e Hepatites Virais. Brasília: MS; 2019. 272 p.

3. Ministério da Saúde (MS). Secretária de Vigilância em Saúde. Sifilis 2019. Boletim Epidemiológico Especial. Volume: 49. Brasilia: MS; 2019. 48p. 
4. Pan American Health Organization (PAHO). Elimination of mother-tochild transmission of HIV and syphilis in the Americas. Update 2016. Washington: PAHO; 2017. 62p.

5. Campos ALA, Araujo MAL, Melo, SP, Gonçalves, MLC. Epidemiology of gestational syphilis in Fortaleza, Ceará State, Brazil: an uncontrolled disease. Cad Saúde Pública. 2010;26(9):1747-55.

6. Lima VC, Mororó RM, Martins MA, Ribeiro, SM, Linhares, MSC. Epidemiological profile of cases of congenital syphilis a mid-sized municipality of Brazil northeast. J Health Biol Sci. 2017;5(1):56-61.

7. Costa CC, Freitas LV, Sousa DMN, Oliveira LL, Chagas ACMA, Lopes MVO, et al. Congenital syphilis in Ceará: epidemiological analysis of one decade. Rev Esc Enferm. 2013;47(1):152-159.

8. Kissinger PJ, Niccolai LM, Magnus M, Farley TA, Maher JE, RichardsonAlston G, Dorst D, Myers L, Peterman, TA. Partner notification for HIV and syphilis: effects on sexual behaviors and relationship stability. Sex Transm Dis. 2003;30(1):75-82.

9. Nonato SM, Melo APS, Guimarães MDC. Syphilis in pregnancy and factors associated with congenital syphilis in Belo Horizonte-MG, Brazil, 2010-2013. Epidemiol Serv Saúde. 2015;24(4):681-94.

10. Domingues RMSM, Szwarcwald CL, Souza PRB, Leal MC. Prevalence of syphilis in pregnancy and prenatal syphilis testing in Brazil: Birth in Brazil study. Rev Saúde Pública. 2014;48:766-74.

11. Viellas EF, Domingues RM, Dias MA, Gama SG, Filha MMT, Costa JV, Bastos MH, Leal MC. Prenatal care in Brazil. Cad Saúde Publica. 2014;30(Suppl 1):S1-15.

12. Bampi, JVB, Correa ME, Bet GMS, Marchioro SB, Simionatto S. Descriptive analysis of syphilis cases reported in Mato Grosso do Sul, Brazil identifies failure in treatment. Rev Soc Bras Med Trop. 2019;52(e20180026);1-4.

13. Aquino GT, Silva HCG. Profile of the women with syphilis gestational in the State of Santa Catarina in 2012. Arq Catarin Med. 2015;44(4): $72-81$.
14. Macêdo VC, Lira PIC, Frias PG, Romaguera LMD, Caires SFF, Ximenes RAA. Risk factors for syphilis in women: case-control study. Rev Saude Publica. 2017;51(78);1-12.

15. Dantas LA, Jerônimo SHN, Teixeira GA, Lopes TRG, Cassiano AN, Leite de Carvalho JB. Epidemiologic profile of acquired syphilis diagnosed and notified at a maternal-child university hospital. Enfermería Global. 2017;46:237-245.

16. Cavalcante PAM, Pereira RBL, Castro JGD. Syphilis in pregnancy and congenital syphilis in Palmas, Tocantins State, Brazil, 2007-2014. Epidemiol Serv Saúde. 2017;26:255-264.

17. Ministério da Saúde (MS). Secretaria de Vigilância em Saúde. Protocolo clínico e diretrizes terapêuticas para atenção integral às pessoas com infecções sexualmente transmissíveis. Brasília: MS; 2015. 122p.

18. Coutinho LRP, Barbieri AR, Santos MLM. Reception in Primary Health Care: an integrative review. Saúde Debate. 2015;39(105):514-24.

19. Teixeira MA, Araújo MAL, de Melo SP, Gonçalves MLC. Epidemiological and sociodemographic profile of children infected congenital syphilis in Jequié/Bahia. Com Rev Saúde. 2015;11(3):303-13.

20. Ministério da Saúde (MS). Secretaria de Gestão do Trabalho e da Educação na Saúde. Política Nacional de Educação Permanente em Saúde: o que se tem produzido para o seu fortalecimento? Brasília: MS; 2018. 78p.

21. Cavalcanti JRD, Ferreira JA, Henriques AH B, Morais GSN, Trigueiro JS, Torquato IMB. Integral Assistance to Men's Health: needs, barriers and coping strategies. Esc Anna Nery. 2014;18(4):628-34.

22. Teixera DBS, Cruz SPL. Health care for the human: analysis of its strength is search for the health services. Rev Cuba Enferm. 2016;32(4):126-136.

23. Cavalcante EGF, Miranda MCC, Carvalho AZFHT, Lima ICV, Galvão MTG. Partner notification for sexually transmitted infections and perception of notified partners. Rev Esc Enferm. 2016;50(3):450-7.

24. Domingues RMSM, Leal MC. Incidence of congenital syphilis and factors associated with vertical transmission: data from the Birth in Brazil study. Cad Saude Publica. 2016;32(6):e00082415. 